\title{
The Identification of Recurrent Laryngeal Nerve by Injection of Blue Dye into the Inferior Thyroid Artery
}

\author{
Amr Salah, Mohamed Mamdoh, Nader Abd-Elhamid* \\ Surgical Oncology Unit, Faculty of Medicine, Al-Azhar University, Cairo, Egypt \\ *Corresponding author: Nader Abd-Elhamid, E-mail: naderzaid1969@yahoo.com \\ Mohamed Mamdoh, E-mail: M_asar@windowslive.com
}

\begin{abstract}
Background: Thyroidectomy creates a potential risk for injury of the recurrent laryngeal nerve (RLN). The identification and dissection of the RLN is the gold standard for preserving its function.

Aim of the work: was to evaluate the value of injection of methylene blue dye into the inferior thyroid artery for help of the identification and dissection of RLN.

Patients and Methods: This study included 60 selected patients who underwent thyroid surgery divided into 2 groups. In group A (30 patients) the branches of the inferior thyroid artery (ITA) near to the capsule of the thyroid lobe were isolated, and then $0.5 \mathrm{ml}$ methylene blue dye was injected into the artery. In group B (30 patients) the RLN identified without help of dye to be compared with group A cases.

Results: During injection of dye bleeding from the ITA occurred in 7 patients. The identification of the RLN within the painted tissue was succeeded 28 patients and failed in 2 patients due to extravasation of the dye. Regarding the amount of blood loss, there was a significant difference between the groups as the average amount of blood loss in group A was $85 \pm 22 \mathrm{ml}$ (range 70-120) and in group $\mathrm{B}$ was $105 \pm 37 \mathrm{ml}$ (range 90-160) $\mathrm{P}=0.01$. Also, by comparing the time taken for RLN identification in one side, there was a significant difference between the groups, as the median time taken for single RLN identification in each case in group A was $9 \pm 2 \mathrm{~min}$ (range 7-12 min) and in group B was $14 \pm 3$ min (range 10-20 min) $\mathrm{P}=0.008$.

Conclusion: the injection of methylene blue dye into the inferior thyroid artery or its branches is a feasible, effective, reliable way that can be used as a method for the identification of the RLN during thyroidectomy.
\end{abstract}

Keywords: Methylene blue, recurrent laryngeal nerve, thyroid surgery

\section{Introduction}

Thyroidectomy is one of the most frequent operations performed in iodine-deficient regions. The main postoperative complications are recurrent laryngeal nerve (RLN) palsy and hypoparathyroidism (1). Although the incidence of RLN injury after thyroidectomy widely varies in the literature, it was ranging from $0.4 \%$ to $7.2 \%$ for temporary paresis and from $0 \%$ to $5.2 \%$ for permanent paralysis ${ }^{(2)}$. Several factors influence the likelihood of injury to the nerve, including the underlying disease (substernal goiter, malignancy, Graves disease, etc.), the extent of resection, and the experience of the surgeon. The standard method for RLN preservation during thyroidectomy is routine visual identification of the nerve ${ }^{(3)}$. RLN palsy includes intra-operative damage to the anatomic integrity of the nerve through thermal injury or axon damage by excessive strain during tracheal intubation, and post-operatively by edema, hematoma, and neuritis caused by scar tissue ${ }^{(4)}$.

In 1923, Frank Lahey emphasized the importance of RLN and developed a standard technique for its identification and exposure during thyroidectomy. Since Lahey, identification and dissection of RLN is the gold standard of preserving its function. Identification of RLN has decreased the rates of transient or permanent nerve injury during thyroid operations ${ }^{(5)}$. There are several approaches to identify the RLNs depending on the surgeon preference. But in some cases it may be still quite difficult to localize the RLNs, and in these situations, blue dye injection into the inferior thyroid artery or its branches may be useful to identify the RLN ${ }^{(6)}$.

The aim of this work was to evaluate the value of injection of methylene blue dye 
into the inferior thyroid artery for help of the identification and dissection of RLN.

\section{Patients and Methods}

This prospective study included a total of 60 patients who had benign or malignant disorder and eligible for thyroidectomy with intact vocal cords, attending at Surgical Oncology Unit, Faculty of Medicine, Al-Azhar University, Cairo. Approval of the ethical committee and a written informed consent from all the subjects were obtained. This study was conducted between December 2017 and June 2018.

The patients were divided into two groups; group A, 30 patients who were allocated to the injection of methylene blue dye into the inferior thyroid artery, and group B, 30 patients with conventional RLN dissection without dye injection.

Under general endotracheal anesthesia, the patients were placed in a supine position with the neck extended. A low collar incision was made and carried down through the subcutaneous tissue and Platysma muscle. Superior and inferior sub-Platysmal flaps were developed, and the strap muscles were separated vertically in the midline and retracted laterally. The thyroid lobe was bluntly dissected free from its investing fascia and rotated medially. The middle thyroid vein was ligated. The superior pole vessels were ligated adjacent to the thyroid lobe. The inferior thyroid artery trunk identified and dissected toward the gland. In group B, the RLNs were identified in the triangle bounded by ITA above, trachea medial and carotid sheath lateral. With cautious dissection layer by layer parallel to the suspected RLN course. With continuous fascia separation the RLN trunk will be visualized as white longitudinal structure passing from thorax upwards in the neck in relation to inferior thyroid vessels.

In group A, instead of conventional RLN identification and visualization the terminal branches of ITA entering the gland were identified and isolated near the capsule of the gland for methylene blue injection. $0.5 \mathrm{ml}$ of methylene blue dye was injected into the terminal branch of ITA after identification of parathyroid branches. (Figure 1).

The RLNs were identified in dyed area (the nerve appeared white in blue tissue). Failures of RLN identification in dyed region indicate its identification below as in group B of patients. Once the nerve and parathyroid glands were identified and dissected, the thyroid lobe was removed from its tracheal attachments by dividing the ligament of Berry. The contralateral thyroid lobe was removed in a similar method. RLN integrity after surgery was assessed with laryngoscopy within 2 weeks of operation.

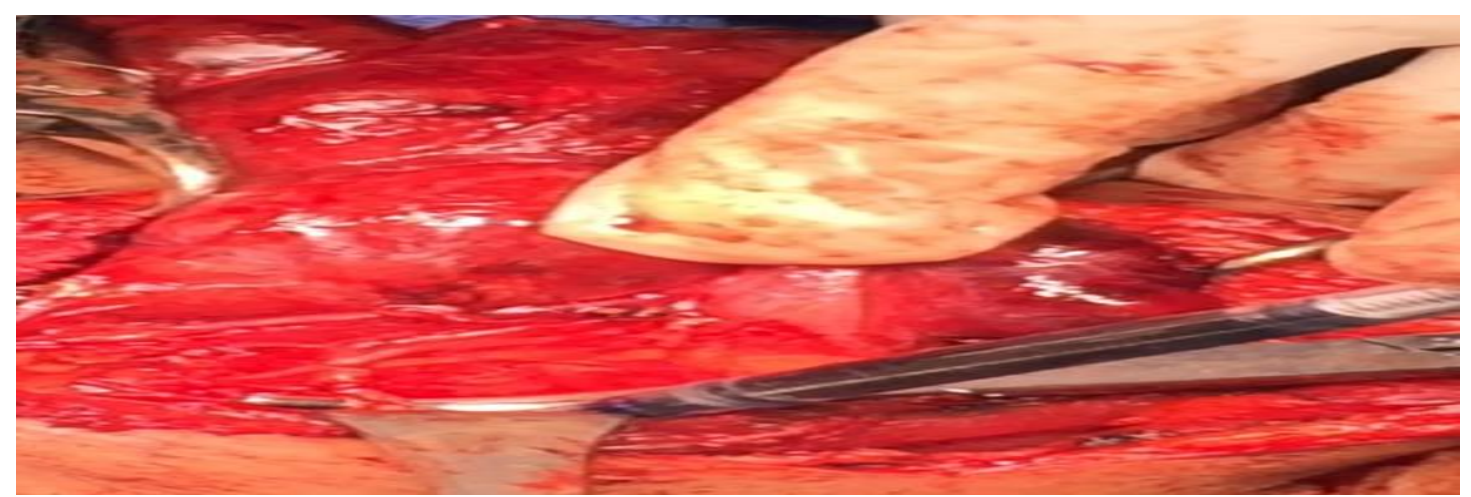

Figure 1. Identification of inferior thyroid artery.

\section{Statistical Analysis:}

All results were analyzed using SPSS version 17. For non-parametric data, number, percent, quantitative data, mean, SD and ranges were used. For comparison of qualitative data, Chisquared test, and student's t test were used. $\mathrm{P}$ values $>0.05$ were considered to be statistically non-significant. $\quad \mathrm{P}<0.05$ was considered significant and $\mathrm{P}<0.001$ was considered highly significant.

\section{Results}

This study included 60 patients (46 females and 14 males) with age ranging from 20-60 years. Regarding the diagnosis of the patients, benign goiter was found in 54 patients (41 
patients with multi nodular goiter (MNG), 9 females with Solitary thyroid nodule, and 4 patients with Hashimoto thyroiditis). In addition, malignancy was found in six patients Table 1: demographic data of cases $(n=60)$ (two males and four females). 51 patients underwent total thyroidectomy while 9 patients performed hemi-thyroidectomy (table 1).

\begin{tabular}{|c|c|c|}
\hline & Median & Range \\
\hline Age (years) & 32 & $20-60$ \\
\hline \multirow{2}{*}{ Body mass index $\left(\mathrm{kg} / \mathrm{m}^{2}\right)$} & 21.5 & $19-35$ \\
\hline & Number & Percentage \\
\hline $\begin{array}{lll}\text { Sex: } & & \\
& \bullet & \text { Males } \\
& \bullet & \text { Females }\end{array}$ & $\begin{array}{l}14 \\
46\end{array}$ & $\begin{array}{l}23.3 \% \\
76.7 \%\end{array}$ \\
\hline $\begin{aligned} \text { Diagnosis : } & \\
\bullet & \text { MNG } \\
\bullet & \text { Solitary thyroid nodule } \\
\bullet & \text { Hashimoto thyroiditis } \\
\bullet & \text { Malignant goiter }\end{aligned}$ & $\begin{array}{l}41 \\
9 \\
4 \\
6\end{array}$ & $\begin{array}{l}58.3 \% \\
15 \% \\
6.7 \% \\
10 \%\end{array}$ \\
\hline $\begin{array}{l}\text { Type of operation } \\
\qquad \quad \text { Total thyroidectomy } \\
\text { - Hemi-thyroidectomy }\end{array}$ & $\begin{array}{c}51 \\
9\end{array}$ & $\begin{array}{l}85 \% \\
15 \%\end{array}$ \\
\hline
\end{tabular}

Among the 60 patients, the trunk of inferior thyroid artery was identified and dissected, and the dye was injected in group A patients $(\mathrm{n}=$ 30). The injection was followed by bleeding from the ITA in 7 patients. The identification of the RLN in the painted area was succeeded in 28 patients (93.3\%) (Figure 2). and failed in 2 patients due to extravasation of the dye. Regarding the amount of blood loss, there was a significant difference between the groups as the average amount of blood loss in group A was $85 \pm 22.2 \mathrm{ml}$ (range 70-120) and in group B was $105 \pm 37.3 \mathrm{ml}$ (range 90-160) $\mathrm{P}=0.01$. Regarding the time taken for RLN identification in one side, there was a significant difference between the groups, as the median time taken for single RLN identification in each case in group A was $9 \pm 2.1 \mathrm{~min}$ (range 7-12 min) and in group $B$ was $14 \pm 3.4 \mathrm{~min}$ (range 10-20 min) $\mathrm{P}=0.008$ (table 2).

There was no operative mortality. Persistent or transient vocal cord paralysis was not encountered in any patients as seen in postoperative laryngoscopy. Out of the included 60 patients, only two patients developed hoarseness of voice in group B which was transient and the voice returned again. Regarding the postoperative calcium level, only four patients suffered from hypocalcaemia manifestations which were transient and respond well to short term medical treatment.

Table 2: the result of intraoperative findings of ITA injection and identification of RLN 
The Identification of Recurrent Laryngeal Nerve by Injection of Blue Dye into the Inferior Thyroid Artery

\begin{tabular}{|l|l|l|l|}
\hline & \multicolumn{1}{|c|}{$\begin{array}{c}\text { Group A } \\
(\mathrm{n}=30)\end{array}$} & $\begin{array}{c}\text { Group B } \\
(\mathrm{n}=30)\end{array}$ & $\begin{array}{c}\mathrm{P} \\
\text { value }\end{array}$ \\
\hline $\begin{array}{c}\text { Amount of blood loss } \\
\text { in ml during RLN } \\
\text { identification } \\
\text { (median - Range) }\end{array}$ & $\begin{array}{c}85 \pm 22.2 \\
(70-120)\end{array}$ & $\begin{array}{c}105 \pm 37.3 \\
(90-160)\end{array}$ & 0.01 \\
\hline $\begin{array}{c}\text { Time taken for single } \\
\text { RLN identification in } \\
\text { minutes (median - } \\
\text { Range) }\end{array}$ & $9 \pm 2.1$ & $14 \pm 3.4$ \\
$(7-12)$ & $(10-20)$ & 0.008 \\
\hline
\end{tabular}

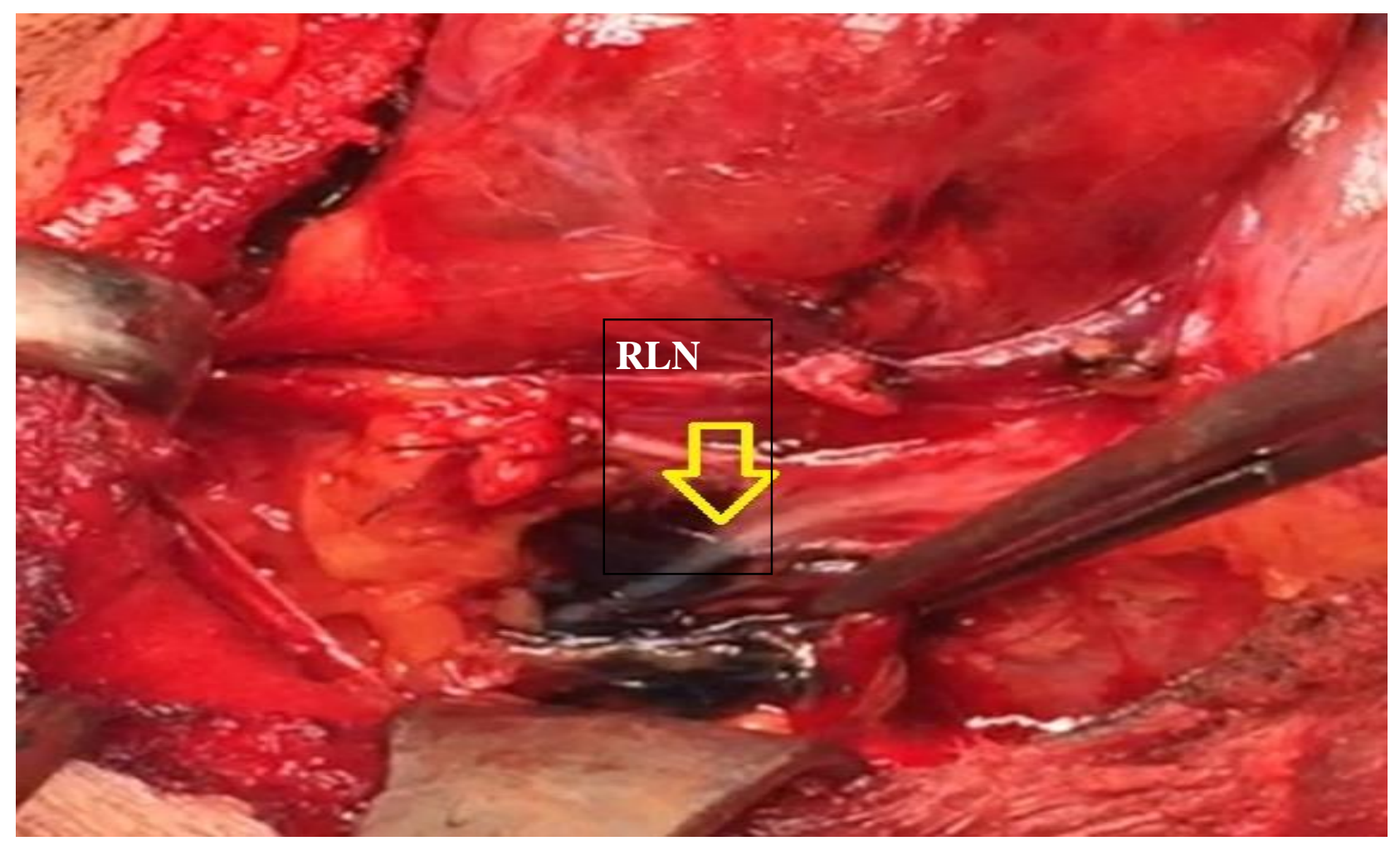

Figure 2. The Recurrent laryngeal nerve in the dyed surrounded tissue.

\section{Discussion}

Thyroidectomy creates a potential risk for the parathyroid glands and for the laryngeal nerves. Injury to the RLN results in acute paralysis of the vocal fold on the affected side, which leads to dysphonia, dysphagia, and aspiration problems ${ }^{(7)}$. The first routine pattern for identifying the nerve is to find the inferior thyroid artery and to use it as an anatomic marker. However, because of the numerous variations of this neurovascular relationship altered also by the pathologic condition of the gland, identification of the ITA does not assure consequent identification and preservation of the $\mathrm{RLN}^{(4)}$.

Interestingly, the cases whose RLN couldn't be seen may be have variation in the anatomy of the nerve like; non-recurrent nerve or deviation from the conventional rout of the nerve. Whatever, our result showed that the nerve was not injured even in difficult cases. Our results agree with a big retrospective study of Shen $\boldsymbol{e t}$ al. ${ }^{(8)}$, on 5344 cases to determine the value of identification and dissection of the RLN during thyroid surgery with respect to preventing RLN 
injury, they found that the rate of RLN injury was statistically significant between the groups (2.2\% in dissection group compared to $10.7 \%$ in non-dissection group, $\mathrm{P}<0.01$ ).

Our results showed great feasibility and reliability of intra-arterial injection of methylene blue into the ITA for easy identification of RLN during the surgery and therefore, avoid the injury of this nerve. This result agree with Hepgul et al. whom performed the same technique but for the difficult cases only and they found that RLN was clearly visualized, in all patients, all RLNs were identified along their course in the dyed surrounding tissue, and no RLN palsy was encountered ${ }^{(6)}$. In our study, in first few cases we faced difficulties in injection of dye in 2 cases with extravasation of dye and failure in RLN identification near to thyroid gland.

Also our results showed that less time till identification of the nerve and less blood loss in the injection group comparing with the group of meticulous dissection of the nerve without dye. To our knowledge there is no publications comparing the time of RLN dissection in dyed and non-dyed cases. While Liu and Chou, 2014 comparing the time of RLN dissection between cadaveric and clinical groups ${ }^{(9)}$.

There are a lot of methods used for help in identification and dissection of RLN in which our results of blue dye injection in ITA were comparable with other methods like spraying of methylene blue dye during the surgery on the surrounding structures for RLN identification (10). Furthermore, it seems that the use of blue dye in RLN identification is feasible as neuromonitoring technique (NMT) for RLN identification during thyroidectomy, in which the rate of RLN identification by NMT was $91.7 \%$ compared to $47.7 \%$ without NMT ${ }^{(11)}$.

In conclusion, It could be concluded that injection of methylene blue dye into the inferior thyroid artery or its branches is a feasible, effective, reliable way that can be used as a method for the identification of the RLN during thyroidectomy. Therefore, this technique could effectively help the conventional visual identification of the nerve to get the most desired outcome and save the nerve from the injury.

\section{Références}

1. Chiang FY, Lee KW, Chen HC, Chen HY, Lu IC, Kuo WR, Hsieh MC and Wu CW(2010): Standardization of intraoperative neuromonitoring of recurrent laryngeal nerve in thyroid operation. World J Surg., 34: 223-9.

2. Rulli F, F. Ambrogi V, Dionigi G, Amrhassankhan S, MineoTC, Ottaviani F, Buemi A, Stefano P D and Mourad M (2014): Meta-analysis of recurrent laryngeal nerve injury in thyroid surgery with or without intraoperative nerve monitoring. ACTA Otorhinolaryngo Itali,34: 223-9.

3. Calo PG, Pisano G, Medas F, Pittau MR, Gordini L, Demontis $R$ and Nicolosi A (2014): Identification alone versus intraoperative neuromonitoring of the recurrent laryngeal nerve during thyroid surgery: experience of 2034 consecutive patients. J Otolaryngol Head and Neck Surg. , 43:16-23.

4. Shindo ML, Wu JC and Park EE(2005): Surgical anatomy of the recurrent laryngeal nerve revisited. J Otolaryngol Head and Neck Surg. , 133(4):514-19.

5. Ardito G, Revelli L, D'Alatri L, Lerro V, Guidi ML, Ardito F (2004): Revisited anatomy of the recurrent laryngeal nerves. Am J Surg., 187(2):249-53.

6. Hepgul G, Kucukyilmaz M, Koc O, Duzkoylu Y, Sari YS and Erbil Y (2013): The identification of recurrent laryngeal nerve by injection of blue dye into the inferior thyroid artery in elusive locations. J Thyroid Res., ID:539274, https://www.hindawi.com/journals/jtr/2013/5 39274/

7. Mattsson $P$, Hydman $J$ and Sevensson M (2015): Recovery of laryngeal function after intraoperative injury of the recurrent laryngeal nerve. Gland Surg. , 4(1): 27-35.

8. Shen C, Xiang M, Wu H, Ma Y, Chen $L$ and Cheng $L$ (2013): Routien exposure of recurrent laryngeal nerve in thyroid surgery can prevent nerve injury. Neural Regen Res., 8(17):1568-75.

9. Liu SC and Chou YF (2014): A rapid and accurate technique for identification of 
the recurrent laryngeal nerve. Ann Otol Rhinol Laryng.,123(11): 805-10.

10. Basavaraj PK, Patil RS, Rao SUP and Panicker R (2018): Study on the Use of Methylene Blue Spray in Identification of Recurrent Laryngeal Nerve During Thyroid Surgery. JCDR. , 12(5): MC01-MC04.
11. Wojtczak B, Sutkowski K, Kaliszewski $K$, Gold $M$ and Barczyriski $M$ (2017): Experience with intraoperative neuromonitoring of the recurrent laryngeal nerve improves surgical skills and outcomes of non-monitored thyroidectomy. Langenbecks Arch Surg.,402(4): 709-17. 